\title{
Multistate Models to Predict Development of Late Complications of Type 2 Diabetes in an Open Cohort Study
}

This article was published in the following Dove Press journal: Diabetes, Metabolic Syndrome and Obesity: Targets and Therapy

\author{
Roqayeh Aliyari' \\ Ebrahim Hajizadeh' \\ Ashraf Aminorroaya $\mathbb{D}^{2}$ \\ Farshad Sharifi (iD) ${ }^{3}$ \\ Iraj Kazemi ${ }^{4}$ \\ Ahmad-Reza Baghestani ${ }^{5}$ \\ 'Department of Biostatistics, Faculty of \\ Medical Sciences, Tarbiat Modares \\ University, Tehran, Iran; ${ }^{2}$ Isfahan \\ Endocrine and Metabolism Research \\ Center, Isfahan University of Medical \\ Sciences, Isfahan, Iran; ${ }^{3}$ Elderly Health \\ Research Center, Endocrinology and \\ Metabolism Population Sciences Institute, \\ Tehran University of Medical Sciences, \\ Tehran, Iran; ${ }^{4}$ Department of Statistics, \\ Faculty of Sciences, University of Isfahan, \\ Isfahan, Iran; ${ }^{5}$ Department of \\ Biostatistics, Physiotherapy Research \\ Center, Faculty of Paramedical Sciences, \\ Shahid Beheshti University of Medical \\ Sciences, Tehran, Iran
}

Background: Increase in the prevalence of type 2 diabetic mellitus (T2DM) as a complex disease, its complications, and spread has become a dominant global health threat in recent decades.

Objective: The aim of the current study was to investigate the impact of risk factors and transition probability on the development and progression of the late complications of T2DM.

Methods: This study was an open cohort one which was conducted at Isfahan Endocrine and Metabolism Research Center (IEMRC). The data were collected from 1993 to 2018. The sample size consisted of 2519 adults diagnosed with type 2 diabetes. We applied the homogeneous multistate models including no complication, retinopathy alone, coronary artery disease (CAD), microalbuminuria, retinopathy and $\mathrm{CAD}$, and the final absorbing mortality states.

Results: Based on our results, time-varying hypertension strongly intensified the hazard of transition to mortality in $\mathrm{CAD}$, no complication, $\mathrm{CAD}$ and retinopathy, and retinopathy patients by 4.99, 4.09, 3.42, and 2.65 times, respectively. Hypertension seemed to be a potential factor for the transition of microalbuminuria to no complication in diabetic patients. One-unit increase in LDL increased the hazard ratio of transition from CAD, and retinopathy and $\mathrm{CAD}$ to mortality by $1.8 \%$ and $2.4 \%$, respectively. Moreover, one level increase in time-varying $\mathrm{HbA} 1 \mathrm{c}$ increased the hazard ratio of transition to retinopathy and mortality among no complication diabetic patients by $30 \%$ and $67 \%$, respectively. One level increase in time-varying $\mathrm{HbAlc}$ also intensified the hazard ratio of transition from retinopathy to mortality by $45 \%$. The same level of increase in time-varying HbAlc also intensified the hazard ratio of transition from $\mathrm{CAD}$ alone to $\mathrm{CAD}$ and retinopathy, and microalbuminuria to retinopathy by $26 \%$ and $50 \%$, respectively.

Conclusion: In addition to glycemic control, our study indicates that controlling hypertension and hyperlipidemia is more effective in reducing mortality and the diabetic macro- and microvascular complications.

Keywords: T2DM, hypertension, CAD, microalbuminuria, retinopathy, diabetics complications, multistate models, transition probability

\section{Introduction}

Increase in the prevalence of $\mathrm{T} 2 \mathrm{DM}$ as a complex disease, ${ }^{1}$ its complications, and spread have become a dominant global health threat ${ }^{2}$ in recent decades. The late complications of diabetes mellitus are divided into two categories: macrovascular and microvascular which affect eyes, kidneys, nerves, and cardiovascular system. ${ }^{3}$ In

Ashraf Aminorroaya

Isfahan Endocrine and Metabolism

Research, Isfahan University of Medical

Sciences, Isfahan, Iran

Tel +983133359933

Fax +983133373733

Email aminorroaya@med.mui.ac.ir 
previous observational studies in 38 countries, the raw prevalence of macrovascular and microvascular complications was reported to be $12.7 \%$ and $18.8 \%$ (chronic kidney disease $5.0 \%$, proliferative diabetic retinopathy $7.5 \%$, and albuminuria $4.3 \%$ ), respectively. The macrovascular complications included coronary artery disease (8.2\%), heart failure (3.3\%), and stroke (2.2\%). ${ }^{4,5}$ An updated systematic review and meta-analysis of patients with T2DM in Iran showed that the combined prevalences of cardiovascular disease, retinopathy, and neuropathy were 33\% (95\% CI: $16-49 \%$ ), 36\% (95\% CI: $27-45 \%$ ), $43 \%$ (95\% CI: $27-60 \%$ ), respectively. ${ }^{6}$ Moreover, the prevalence of microalbuminuria was $26 \%{ }^{7}$ Cardiovascular disease caused by hypertension and dyslipidemia ${ }^{8}$ is the major cause of mortality and morbidity in T2DM patients. Due to the same underlying risk factors, diabetes and hypertension are related to each other. ${ }^{2,8}$ The mortality rate of coronary artery disease increases as a function of both serum cholesterol levels and hypertension. ${ }^{8}$ Good control of hypercholesterolemia and hypertension reduces the relative cardiovascular risk among diabetic patients. ${ }^{9}$ Retinopathy which is characterized by increased vascular permeability, is the most common microvascular diabetic complication, while coronary heart disease is the leading cause of macrovascular complication. ${ }^{10,11}$ Severe diabetic retinopathy is associated with the time from onset of diabetic mellitus, hypertension, HbA1c levels, ${ }^{12}$ and gender. ${ }^{13,14}$ The postponement of diabetic retinopathy progression can be achieved by controlling the hyperglycemia and hypertension in individuals with diabetes mellitus. ${ }^{14}$ $\mathrm{HbAlc}$ is a proposed screening tool for diabetes which has less intra-individual variation and is a reliable tool to anticipate both micro-/macro-vascular complications. ${ }^{15}$ Microalbuminuria is associated with cardiovascular events in T2DM. High blood pressure, cholesterol, and blood glucose, regular urinary albumin excretion, are strong modifiable risk factors of diabetes complications in patients with type 2 diabetes and should be assessed/measured. ${ }^{15,16}$ Despite further attempts and educational programs to prevent and control diabetes, Iran is one of the countries with the highest number (5.4 million) of diabetes in the Middle East and North Africa. In this region (MENA), the age-adjusted diabetes prevalence was $12.2 \%$ in 2019 which is projected to increase by $38.8 \%$ by 2030 and $96.5 \%$ by $2045 .{ }^{12}$ In longitudinal time-to-event studies, the progression of different complications of the disease can only be analyzed using advanced statistical methods. ${ }^{17}$ Multistate model describes the changes in disease's status over time, and more specifically, it is concerned about not only the outcome states but also subsequent events after the first state. The starting and final states do not have to be single and patients pass through more than one intermediate state. ${ }^{18}$ Multistate model is a useful tool to describe a process of movement through a finite number of states in a continuous time. Furthermore, by using this model, we can also estimate the rate of progression, assess the effects of individual risk factors, and evaluate the survival rates or prognostic forecasting. ${ }^{18,19}$ A small number of studies have considered the transit states from one diabetic complication to another. The application of multistate models in diabetes has been limited to one type of complications such as retinopathy stages in diabetic individuals. The current research demonstrates the probability of transfer to some microvascular or macrovascular complications and also examines the impact of complication burden and major risk factors such as $\mathrm{HbAlc}$, hypertension, gender body mass index, total cholesterol, low-density lipoprotein, and high-density lipoprotein using a homogeneous Markova time-continues multi-state model.

\section{Methods}

\section{Study Design, Participants, and Sampling Strategy}

This study was an open cohort study conducted at IEMRC. The data were collected and stored in a clinical information system from 1993 to 2018 . The sample size consisted of 2519 type 2 diabetic patients.

The inclusion criteria were age greater than 18 years old and at least two follow-up visits per year. While the exclusion criteria were pregnancy, other types of diabetes, and emigration. Details about the methodology used in the current study including sampling method, survey instruments, and data entry have been described elsewhere. ${ }^{20}$ The follow-up tests were carried out using standards of medical care in diabetes recommended by the American Diabetes Association (ADA). The ethical approval for this study accordance with the Helsinki Declaration was obtained from the Endocrine and Metabolism Research Center, Isfahan University of Medical Sciences and the University of Tarbiat Modares, Iran. Informed consent was obtained from all participants.

\section{Instruments}

Diagnosis of T2DM: the diagnostic criteria for T2DM were based on the ADA criteria. ${ }^{21}$

Diagnosis of retinopathy: the diabetic individuals were referred to an ophthalmology clinic; the diagnosis of retinopathy was based on indirect ophthalmoscopy through 


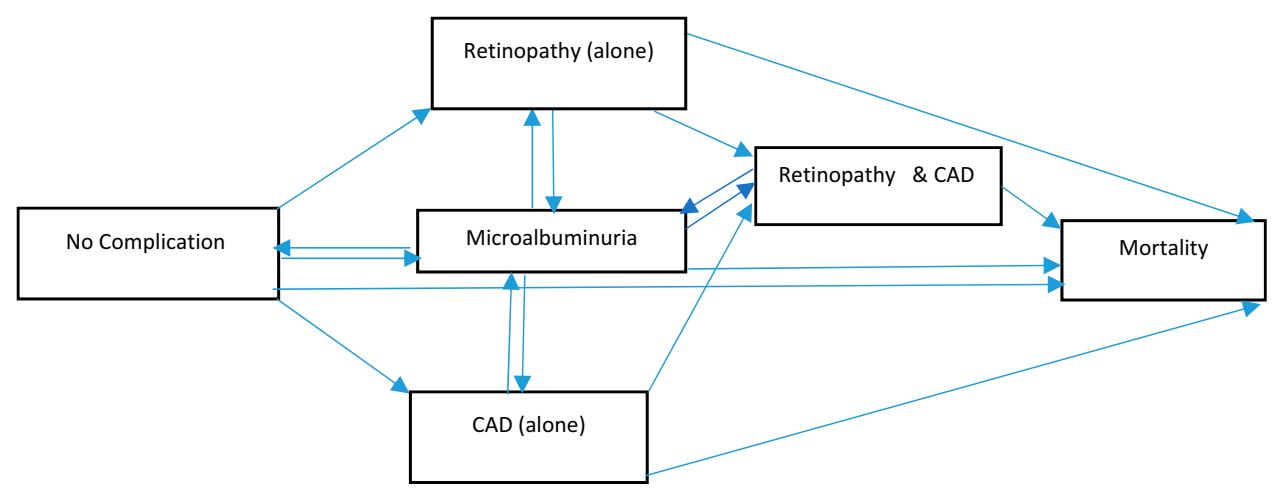

Figure I Theoretical transition of complications in patients with type 2 diabetes.

dilated pupils. In patients with non-proliferative or proliferative diabetic retinopathy, the diagnosis of diabetic retinopathy was only considered by a physical examination by an ophthalmologist, ${ }^{10}$ In asymptomatic patients, retinopathy was evaluated annually/in a one-year time frame.

Coronary artery diseases: clinical symptoms, signs, and changes in the electrocardiogram in favor of ischemia or angiography that shows coronary artery stenosis. The assessment of CAD consisted of a 12-lead resting electrocardiogram and a positive response to the angina pectoris section on the Rose questionnaire and self-reported medical history. ${ }^{22}$

Microalbuminuria diagnosis: microalbuminuria is defined as an albumin excretion of 30 to $300 \mathrm{mg}$ per day. ${ }^{23}$ In this study, we only considered microalbuminuria (not macroalbuminuria). Most of the patients with macroalbuminuria were referred to private clinics, and, therefore, we were not able to follow-up their treatment processes. HbA1c was measured using a DSS machine and the ion-exchange chromatography method.

\section{Variables}

Gender, body mass index, total cholesterol, low-density lipoprotein, high-density lipoprotein, hypertension (categorized as systolic/diastolic [140/90 $\mathrm{mmHg}$ or greater] or the use of antihypertensive medications), and $\mathrm{HbAlc}$ were independent variables that were included in statistical modeling. The details on the measurements of the variables have been described elsewhere. ${ }^{24}$

\section{Statistical Analysis}

In this study, a multistate time-to-event model was used as the main statistical method for modeling five incorporate transient states that represent T2DM without or with complications including retinopathy, $\mathrm{CAD}$, microalbuminuria, $\mathrm{CAD}$ and retinopathy, and mortality as the final absorbing state. We assumed that a continuous-time homogenous Markov process explores the transition intensity times between these finite complication states in diabetic patients (state 1: no complication, state 2: retinopathy, state $3: \mathrm{CAD}$, state 4 : microalbuminuria, state 5 : retinopathy and $\mathrm{CAD}$, and state 6 : mortality). The theoretical transition between these states is shown in Figure 1.

We specified the multistate models in which the transition intensity matrix is conducted by the Q matrix.

$$
Q=\left(\begin{array}{cccccc}
q_{11} & q_{12} & q_{13} & q_{14} & - & q_{16} \\
- & q_{22} & - & - & q_{25} & q_{26} \\
- & - & q_{33} & - & q_{35} & q_{36} \\
q_{41} & q_{42} & q_{43} & q_{44} & - & q_{46} \\
- & - & - & - & q_{55} & q_{56}
\end{array}\right)
$$

In the Q matrix, $q_{35}$ shows the transition from state 3 to state 5. By fitting the homogenous Markov multistate model, we estimated the transition intensity of $Q$ matrix which represents the risk of instant movement from state $r$ to state $s$. As shown in the below formula, $t$ is the continues-time and $z(t)$ can be a set of time-varying or individual-specific explanatory variables.

$$
q_{r s}(t, z(t))=P(S(t+\delta t))=s \mid S(t)=r / \delta t
$$

The probability of the subject's next move from state $r$ to state $s$ is $-q_{r s} / q_{r r}$.

Due to specified Q matrix transitions in this model, there are 13 transitions which were numbered in the following order: (i) no complication (initial state) to retinopathy, (ii) no complication to $\mathrm{CAD}$, (iii) no complication to microalbuminuria, (iv) no complication to mortality (absorbing state), (v) retinopathy to retinopathy and $\mathrm{CAD}$, (vi) retinopathy to mortality, (vii) CAD to retinopathy and CAD, (viii) CAD to mortality, (ix) microalbuminuria to no complication, (x) microalbuminuria to retinopathy, (xi) microalbuminuria to CAD, (xii) microalbuminuria to mortality, and (xiii) 
Table I Number of Observed Transitions Between States (Row to Column) During Study Period (25 Years) in the Diabetic Patients

\begin{tabular}{|l|l|l|l|l|l|l|}
\hline & $\begin{array}{l}\text { No } \\
\text { Complications }\end{array}$ & $\begin{array}{l}\text { Retinopathy } \\
\text { (Alone) }\end{array}$ & $\begin{array}{l}\text { CAD } \\
\text { (Alone) }\end{array}$ & Microalbuminuria & $\begin{array}{l}\text { Retinopathy and } \\
\text { CAD }\end{array}$ & Mortality \\
\hline $\begin{array}{l}\text { No complications } \\
\text { Retinopathy (alone) }\end{array}$ & 35196 & 318 & 333 & 276 & 17 & 104 \\
CAD (alone) & 0 & 11785 & 0 & 0 & 69 & 36 \\
Microalbuminuria & 378 & 0 & 12263 & 0 & 108 & 52 \\
Retinopathy and & 0 & 40 & 27 & 3210 & 6810 & 1 \\
CAD & 0 & 0 & 0 & 31 \\
\hline
\end{tabular}

retinopathy and CAD to mortality. It should be noted (see Table 1) that transitions from no complication and microalbuminuria to retinopathy and CAD were not considered, while in spite of inadequate sample size, the transition from microalbuminuria to absorbing state (mortality) was considered. We assumed that the time-dependent covariates in the model remains constant between two observations. By using the multistate models with covariates (sex, time-varying HbA1c, hypertension, LDL, HDL, and BMI), the current study determines the hazard ratio of the factors associated with the progression of diabetic complications among diabetic individuals. The parametric continuous-time multi-state model was used to estimate the effect of the study covariates on transitions between states. ${ }^{25}$ The evaluation of model fitting was done based on improved approximation for panel observations of multi-state Markov models. ${ }^{26}$ The data were analyzed using free $\mathrm{R}$ statistical software version 3.6.0. (msm package).

\section{Results}

In our study, the median (Q1-Q3) follow-up time was 9.01 (4.79-13.38) years. The clinical baseline and demographic characteristics of the patients are reported in Table 2. The mean (SD) age of patients was 49.83 (8.69) years, $9.88 \%$ of them had more than 12 years of education and $34 \%$ of the participants were male. The frequency of the observed transition between states from row to column is shown in Table 1. As shown in Table 3, the probability of remaining in the previous state in no complication patients after $1,2,3,5,10$, and 15 years was $84 \%, 73 \%$, $64 \%, 50 \%, 27 \%$, and $14 \%$, respectively. The transition probability of CAD to mortality after $1,2,3,5,10$, and 15 years was $2.8 \%, 5.6 \%, 8.3 \%, 13.6 \%, 25.9 \%$, and $36.8 \%$, respectively. The transition probability of retinopathy to retinopathy and $\mathrm{CAD}$ after $1,2,3,5,10$ and 15 years was $3.9 \%, 7.4 \%, 10.6 \%, 16 \%, 25.1 \%$, and $29.6 \%$, respectively. As shown in Table 4, the hazard ratio of transition from no
Table 2 Demographic and Clinical Characteristics of Type 2 Diabetic Patients ( $N=2519)$

\begin{tabular}{|c|c|c|}
\hline Variable & Mean (SD) & Median (QI-Q3) \\
\hline Age (years) & $49.83(8.69)$ & $50.00(45-55)$ \\
\hline Diabetes duration (years) & $5.05(5.04)$ & $3.0(1-7)$ \\
\hline Height $(\mathrm{cm})$ & $159.50(8.96)$ & $158.0(\mid 53.0-166.0)$ \\
\hline Weight (kg) & 75.31 (13.37) & $74.0(66.0-83.5)$ \\
\hline Body mass index $\left(\mathrm{kg} / \mathrm{m}^{2}\right)$ & $29.66(4.98)$ & $29.07(26.23-32.63)$ \\
\hline HbAlc (\%) & $8.06(2.02)$ & $7.70(6.60-9.20)$ \\
\hline Fasting plasma glucose (mg/dl) & $161.10(60.06)$ & $147.0(120-187.0)$ \\
\hline Cholesterol (mg/dl) & I $76.4(47.66)$ & $171.0(150.0-196.5)$ \\
\hline TG (mg/dl) & $163.4(97.95)$ & $140.0(102.0-190.4)$ \\
\hline LDL-C (mg/dl) & $88.09(29.49)$ & $83.0(68.0-103.8)$ \\
\hline HDL-C (mg/dl) & $45.18(11.02)$ & $44.0(38.0-51.0)$ \\
\hline $\begin{array}{l}\text { Systolic blood pressure } \\
(\mathrm{mmH})\end{array}$ & $122.8(\mid 6.81)$ & $120.0(110.0-130.0)$ \\
\hline $\begin{array}{l}\text { Diastolic blood pressure } \\
(\mathrm{mmHg})\end{array}$ & $77.92(9.40)$ & $80.0(70.0-80.0)$ \\
\hline $\begin{array}{l}\text { Gender } \\
\text { Female }\end{array}$ & \multicolumn{2}{|l|}{$\begin{array}{l}N(\%) \\
1658(65.84 \%)\end{array}$} \\
\hline \multicolumn{3}{|l|}{ Education levels } \\
\hline Under 12 years education & \multicolumn{2}{|l|}{$2270(90.12 \%)$} \\
\hline $\begin{array}{l}12 \text { years education or } \\
\text { upper }\end{array}$ & \multicolumn{2}{|l|}{$243(9.88 \%)$} \\
\hline $\begin{array}{l}\text { Hypertension }(\geq 140 / 90 \\
\mathrm{mmHg})\end{array}$ & \multicolumn{2}{|l|}{191 (16.16\%) } \\
\hline
\end{tabular}

complication and CAD to mortality for men was 2.04 and 2.78 compared to women. The hazard of transition from microalbuminuria to no complication for women was $37 \%$ which was much higher than that of men. Increasing one unit in $\mathrm{HbA} 1 \mathrm{c}$ increased the hazard of transition from no complications to retinopathy and mortality by $30 \%$ and $67 \%$, respectively. One-unit increase in $\mathrm{HbA} 1 \mathrm{c}$ increased the hazard of transition from retinopathy alone to retinopathy and $\mathrm{CAD}$, and mortality by $16 \%$, and $43 \%$, respectively. Furthermore, HbAlc increased the hazard of transition from $\mathrm{CAD}$ alone to retinopathy and $\mathrm{CAD}$, and 
Table 3 Probability of Next Transition in Baseline (Model Without Covariate) Model According to Passing Different Times (Years)

\begin{tabular}{|c|c|c|c|c|c|c|c|}
\hline From & To & $\begin{array}{l}\text { T=ISt } \\
\text { Year }\end{array}$ & $\begin{array}{l}\text { T=2nd } \\
\text { Year }\end{array}$ & $\begin{array}{l}\text { T=3rd } \\
\text { Year }\end{array}$ & $\begin{array}{l}\text { T=5th } \\
\text { Year }\end{array}$ & $\begin{array}{l}\text { T=loth } \\
\text { Year }\end{array}$ & $\begin{array}{l}T=15 \text { th } \\
\text { Year }\end{array}$ \\
\hline No complications & No complications & 0.843 & 0.729 & 0.639 & 0.496 & 0.267 & 0.144 \\
\hline No complications & Retinopathy (alone) & 0.051 & 0.092 & 0.126 & 0.175 & 0.222 & 0.213 \\
\hline No complications & CAD (alone) & 0.055 & 0.097 & 0.130 & 0.175 & 0.207 & 0.186 \\
\hline No complications & Microalbuminuria & 0.037 & 0.047 & 0.047 & 0.039 & 0.022 & 0.012 \\
\hline No complications & Retinopathy and CAD & 0.003 & 0.010 & 0.020 & 0.047 & 0.128 & 0.199 \\
\hline No complications & Mortality & 0.011 & 0.024 & 0.037 & 0.067 & 0.153 & 0.245 \\
\hline Retinopathy (alone) & Retinopathy (alone) & 0.939 & 0.882 & 0.829 & 0.731 & 0.535 & 0.391 \\
\hline Retinopathy (alone) & Retinopathy and CAD & 0.039 & 0.074 & 0.106 & 0.160 & 0.251 & 0.296 \\
\hline Retinopathy (alone) & Mortality & 0.022 & 0.043 & 0.065 & 0.108 & 0.214 & 0.312 \\
\hline CAD (alone) & CAD (alone) & 0.919 & 0.846 & 0.778 & 0.657 & 0.432 & 0.284 \\
\hline CAD (alone) & Retinopathy and CAD & 0.052 & 0.098 & 0.139 & 0.206 & 0.308 & 0.348 \\
\hline CAD (alone) & Mortality & 0.028 & 0.056 & 0.083 & 0.136 & 0.259 & 0.368 \\
\hline Microalbuminuria & No complications & 0.507 & 0.640 & 0.639 & 0.533 & 0.292 & 0.158 \\
\hline Microalbuminuria & Retinopathy (alone) & 0.049 & 0.092 & 0.128 & 0.182 & 0.236 & 0.228 \\
\hline Microalbuminuria & CAD (alone) & 0.018 & 0.052 & 0.087 & 0.141 & 0.193 & 0.181 \\
\hline Microalbuminuria & Microalbuminuria & 0.419 & 0.195 & 0.106 & 0.051 & 0.023 & 0.130 \\
\hline Microalbuminuria & Retinopathy and CAD & 0.001 & 0.006 & 0.014 & 0.038 & 0.117 & 0.190 \\
\hline Microalbuminuria & Mortality & 0.004 & 0.014 & 0.026 & 0.054 & 0.138 & 0.229 \\
\hline Retinopathy and CAD & Retinopathy and CAD & 0.965 & 0.932 & 0.900 & 0.838 & 0.703 & 0.589 \\
\hline Retinopathy and CAD & Mortality & 0.035 & 0.068 & 0.100 & 0.162 & 0.297 & $0.4 I I$ \\
\hline
\end{tabular}

mortality by $29 \%$ and $37 \%$, respectively. Time-varying hypertension increased the hazard ratio of transition from no complications, retinopathy, $\mathrm{CAD}$, and retinopathy and $\mathrm{CAD}$ to mortality by $3.09,1.65,3.97$, and 2.42 times, respectively. Furthermore, one-unit increase in LDL increased the hazard ratio of transition from $\mathrm{CAD}$, and retinopathy and CAD to mortality by $1.8 \%$ and $2.4 \%$, respectively. One-unit decrease in HDL increased the hazard ratio $(95 \% \mathrm{CI})$ of transition from retinopathy and CAD to mortality by $1.03(1.01,1.05)$ times. There was not any effect of triglyceride on the transition between the complications of the patients. Figure 2 indicates the observed and expected percentages of baseline model prevalence in each state against time (the goodness of baseline model was evaluated and verified $[\mathrm{P} . \mathrm{V}=0.261]$ ).

\section{Discussion}

We found that increase in both systolic and diastolic blood pressure as well as hypertension was positively related to mortality in no complication individuals, individuals with retinopathy, and also individuals with CAD. Furthermore, systolic blood pressure had an important role in the development of retinopathy in non-complication and CAD patients. Several studies have shown that hypertension accelerated the development of diabetic complications such as retinopathy, ${ }^{27}$ nephropathy, ${ }^{28}$ coronary artery diseases, or even independent risk factors for all-cause mortality in individuals with diabetes. ${ }^{29}$ Higher LDL-C in our study was a risk factor for the transition from no complication to retinopathy, $\mathrm{CAD}$, microalbuminuria, and mortality. Another study also reported higher LDL-C levels as an independent risk factor for diabetic retinopathy. ${ }^{30}$ The association of LDL-C level with coronary heart disease in individuals with and without diabetes is well known. ${ }^{31}$ A systematic review on the association of lipid profile and DR indicated that only higher LDL-C levels were associated with DR and other components of lipid profile are not related. ${ }^{32}$

Our findings showed that high levels of time-varying $\mathrm{HbAlc}$ increased the hazard of transition to retinopathy and mortality in diabetic patients. One level increase in time-varying HbAlc increased the hazard ratio of transition to retinopathy and mortality in no complication patients by $30 \%$ and $67 \%$, respectively. We found that HbA1C level was a strong indicator of mortality in diabetic individuals with no complication, CAD, and those with retinopathy. Several studies have shown that there is a positive correlation between $\mathrm{HbA1C}$ level and prevalence of complications. A retrospective observational study reported that diabetic retinopathy and nephropathy 
Table 4 Hazard Ratio $(95 \% \mathrm{Cl})$ of Risk Factors Associated with Diabetic Complications in the Different Multistate Models

\begin{tabular}{|c|c|c|c|c|c|c|}
\hline From & To & HbAIC & LDL & HDL & Cholesterol & TG \\
\hline No complications & $\begin{array}{l}\text { Retinopathy } \\
\text { (alone) }\end{array}$ & $1.30(1.24,1.37)$ & $1.004(1.000,1.008)$ & $1.00(0.99,1.01)$ & $1.006(1.004,1.009)$ & $1.00(0.99,1.01)$ \\
\hline No complications & CAD (alone) & $1.05(0.98,1.12)$ & $1.004(1.000,1.007)$ & $0.99(0.98,1.00)$ & $1.002(0.999,1.005)$ & $0.99(0.98,1.01)$ \\
\hline No complications & Microalbuminuria & $1.06(0.99,1.14)$ & $1.005(1.001,1.009)$ & $1.00(0.99,1.01)$ & $1.001(0.998,1.004)$ & $0.94(0.8 \mathrm{I}, \mathrm{I} .09)$ \\
\hline No complications & Mortality & $1.67(1.44,1.96)$ & 1.031 (I.018, I.044) & $1.00(0.94,1.07)$ & 1.014 (1.010, I.019) & $0.99(0.90,1.10)$ \\
\hline Retinopathy (alone) & $\begin{array}{l}\text { Retinopathy and } \\
\text { CAD }\end{array}$ & $1.16(1.04,1.30)$ & $1.011(1.004,1.018)$ & $1.01(0.99,1.03)$ & $1.013(1.010,1.017)$ & $0.98(0.92,1.06)$ \\
\hline Retinopathy (alone) & Mortality & $1.43(1.29,1.59)$ & $1.032(1.021,1.042)$ & $1.00(0.97,1.04)$ & $1.016(1.013,1.020)$ & $0.97(0.93,1.02)$ \\
\hline CAD (alone) & $\begin{array}{l}\text { Retinopathy and } \\
\text { CAD }\end{array}$ & $1.29(1.18,1.41)$ & $1.005(0.999,1.011)$ & $0.99(0.97,1.01)$ & $1.006(1.001,1.010)$ & $0.99(0.7 \mathrm{I}, \mathrm{I} .37)$ \\
\hline CAD (alone) & Mortality & $1.37(1.15,1.63)$ & $1.018(1.007,1.029)$ & $0.98(0.92,1.03)$ & $1.014(1.010,1.018)$ & $0.99(0.98,1.01)$ \\
\hline Microalbuminuria & No complications & $1.13(1.00,1.27)$ & 1.001 (0.997, I.004) & $1.00(0.99,1.01)$ & $0.999(0.996,1.002)$ & $1.00(0.86,1.18)$ \\
\hline Microalbuminuria & $\begin{array}{l}\text { Retinopathy } \\
\text { (alone) }\end{array}$ & 1.36 (I.II, I.66) & $0.999(0.985,1.014)$ & $1.02(0.99,1.04)$ & $0.998(0.986,1.011)$ & $1.00(0.78,1.27)$ \\
\hline Microalbuminuria & Mortality & $0.66(0.12,3.78)$ & $1.021(0.992,1.052)$ & $1.03(0.98,1.09)$ & 1.017 (0.99I, I.043) & $1.00(0.76,1.29)$ \\
\hline $\begin{array}{l}\text { Retinopathy and } \\
C A D\end{array}$ & Mortality & $1.67(1.46,1.92)$ & $1.024(1.016,1.032)$ & $0.97(0.95,0.99)$ & $1.018(1.015,1.021)$ & $1.00(0.74,1.31)$ \\
\hline-2 log likelihood & & 17330.47 & $18239.9 \mid$ & 18486.14 & 19085.43 & 21426.01 \\
\hline From & To & SBP & DBP & $\begin{array}{l}\text { Time-varying } \\
\text { hypertension } \\
(140 / 90)\end{array}$ & Sex & BMI \\
\hline No complications & $\begin{array}{l}\text { Retinopathy } \\
\text { (alone) }\end{array}$ & $\begin{array}{l}1.019(1.013 \\
1.026)\end{array}$ & $1.016(1.004,1.028)$ & $\begin{array}{l}\text { I.338 (1.029, } \\
\text { I.739) }\end{array}$ & $0.85(0.67,1.07)$ & $0.98(0.95,1.05)$ \\
\hline No complications & CAD (alone) & $\begin{array}{l}\text { I.002 (0.995, } \\
\text { I.009) }\end{array}$ & $0.996(0.985,1.008)$ & $\begin{array}{l}0.829(0.612 \\
1.123)\end{array}$ & $1.19(0.94,1.50)$ & $1.01(0.99,1.04)$ \\
\hline No complications & Microalbuminuria & $\begin{array}{l}0.996(0.988, \\
1.004)\end{array}$ & $0.979(0.966,0.993)$ & $\begin{array}{l}0.569(0.394, \\
0.821)\end{array}$ & $1.12(0.82,1.46)$ & $0.98(0.96,1.02)$ \\
\hline No complications & Mortality & $\begin{array}{l}\text { I.04I (1.030, } \\
\text { I.053) }\end{array}$ & $1.053(1.024,1.084)$ & $\begin{array}{l}4.089(2.285 \\
7.315)\end{array}$ & $0.49(0.27,0.93)$ & $0.88(0.81,0.96)$ \\
\hline Retinopathy (alone) & $\begin{array}{l}\text { Retinopathy } \\
\text { (alone) }\end{array}$ & & & & & \\
\hline Retinopathy (alone) & $\begin{array}{l}\text { Retinopathy and } \\
\text { CAD }\end{array}$ & $\begin{array}{l}1.021(1.010 \\
1.031)\end{array}$ & $1.045(1.022,1.069)$ & $\begin{array}{l}\text { I.79I (1.075, } \\
2.984)\end{array}$ & $0.98(0.60,1.59)$ & $0.99(0.93,1.05)$ \\
\hline Retinopathy (alone) & Mortality & $\begin{array}{l}\text { I.027 (I.014, } \\
1.040)\end{array}$ & $1.036(0.999,1.074)$ & $\begin{array}{l}2.651 \text { (1.289, } \\
5.454)\end{array}$ & $0.52(0.25,1.08)$ & $0.75(0.66,0.84)$ \\
\hline CAD (alone) & CAD (alone) & & & & & \\
\hline CAD (alone) & $\begin{array}{l}\text { Retinopathy and } \\
\text { CAD }\end{array}$ & $\begin{array}{l}1.016(1.006, \\
1.027)\end{array}$ & $1.003(0.986,1.020)$ & $\begin{array}{l}1.322(0.869 \\
2.01 \mathrm{I})\end{array}$ & $0.70(0.47,1.04)$ & $0.97(0.93,1.01)$ \\
\hline CAD (alone) & Mortality & $\begin{array}{l}\text { I.036 (I.026, } \\
\text { I.047) }\end{array}$ & $1.061(1.041,1.081)$ & $\begin{array}{l}4.976(2.553, \\
9.696)\end{array}$ & $0.36(0.20,0.66)$ & $0.88(0.81,0.95)$ \\
\hline Microalbuminuria & No complications & $\begin{array}{l}0.999(0.993, \\
1.006)\end{array}$ & $0.990(0.979,1.002)$ & $\begin{array}{l}0.658(0.487 \\
0.900)\end{array}$ & $1.32(1.06,1.64)$ & $0.98(0.96,1.01)$ \\
\hline Microalbuminuria & $\begin{array}{l}\text { Retinopathy } \\
\text { (alone) }\end{array}$ & $\begin{array}{l}1.020(1.001, \\
1.039)\end{array}$ & $1.044(0.996,1.095)$ & $\begin{array}{l}1.900(0.74 I, \\
4.869)\end{array}$ & $0.5 \mathrm{I}(0.22,1.17)$ & $0.95(0.81,1.12)$ \\
\hline Microalbuminuria & Microalbuminuria & & & & & \\
\hline Microalbuminuria & Mortality & $\begin{array}{l}0.954(0.816, \\
1.116)\end{array}$ & I.III (0.8II, I.522) & 0.954 (big) & $2.67(-)$ & $1.13(0.77,1.65)$ \\
\hline $\begin{array}{l}\text { Retinopathy and } \\
\text { CAD }\end{array}$ & $\begin{array}{l}\text { Retinopathy and } \\
\text { CAD }\end{array}$ & & & & & \\
\hline $\begin{array}{l}\text { Retinopathy and } \\
\text { CAD }\end{array}$ & Mortality & $\begin{array}{l}\mathrm{I} .032(\mathrm{I} .02 \mathrm{I} \\
\mathrm{I} .043)\end{array}$ & $1.055(1.026,1.084)$ & $\begin{array}{l}3.424(1.658 \\
7.069)\end{array}$ & $0.57(0.28,1.13)$ & $0.93(0.86,1.00)$ \\
\hline-2 log likelihood & & 20348.2 & 20448.78 & 20443.58 & 22202.77 & 9559.685 \\
\hline
\end{tabular}




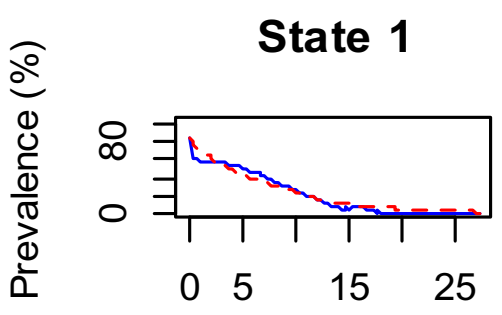

Times

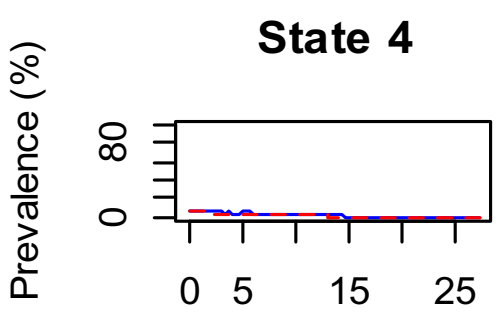

Times

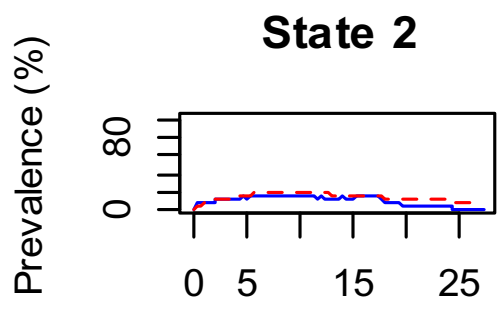

Times

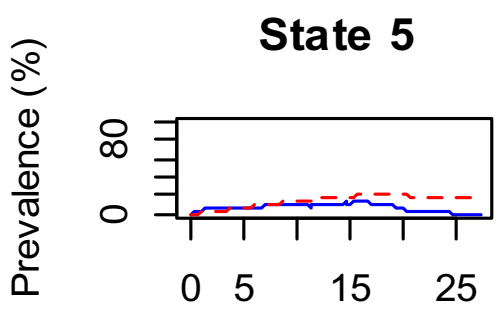

Times

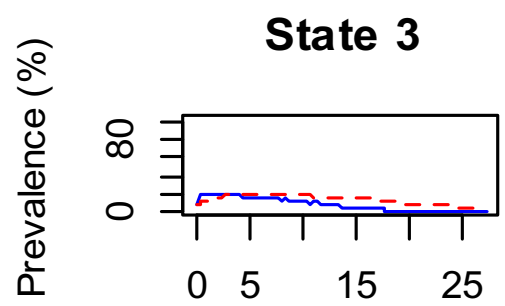

Times

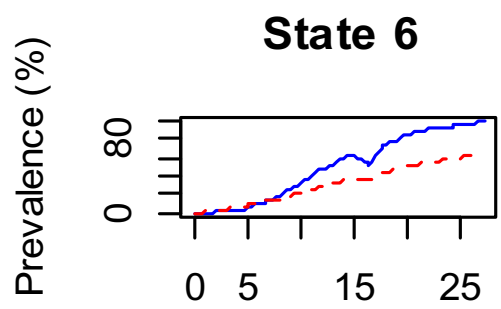

Times

Figure 2 Comparing observed (solid lines) and expected (dashed lines) percentages of prevalence in each state against time according to the baseline model (state I: no complication, state 2: retinopathy, state 3: CAD, state 4: microalbuminuria, state 5: retinopathy and CAD, and state 6: mortality).

were related to hemoglobin Alc which was an indicator of poor control of diabetes mellitus. ${ }^{33}$ Another study also reported that age, disease duration, and HBA1c level were related to microvascular complications of diabetes, while only age was related to macrovascular complication of diabetes, which is in line with our findings as we found that only mortality and retinopathy were associated with higher levels of HbA1C. ${ }^{34}$

In our study, females without complication had $12 \%$ less risk of mortality than males which could be explained by a longer life expectancy in women than men. ${ }^{35}$ In females without complication and with CAD, the risk of mortality was lower than males. This finding is in line with the results of previous studies which reported a lower mortality rate in women than in men with diabetes mellitus. ${ }^{36}$

We found that higher BMI is a significant protective factor for mortality in individuals with diabetes. Mortality transition from no complication individuals as well as diabetic patients with retinopathy and CAD decreased in groups with higher BMI. We did not analyze the effect of BMI on mortality based on the World Health Organization's classification. This finding may be justified with the paradox of obesity which was recently reported in some studies. ${ }^{37,38}$ In older adults, overweight may particularly be accompanied by a lower risk of all-cause and cardiovascular motility. ${ }^{37}$ Furthermore, among type 2 diabetic patients, the U-shaped association of BMI with all- cause mortality with adjusted age, sex, systolic blood pressure, diastolic blood pressure, fasting plasma glucose, total cholesterol, triglyceride, smoking, and diabetes duration has been observed which showed that overweight participants had a significantly lower hazard ratio of mortality than other BMI groups. ${ }^{38}$

We found that with time extension from the diagnosis of diabetes, the probability of being free of complication had a decreasing trend while the probability of mortality and all complications had an incremental trend. A previous study reported that 1-year increase in diabetes duration increases the risk of macrovascular complications and microvascular problems by $13 \%$ and $28 \%$, respectively, in individuals with diabetes mellitus. ${ }^{39}$ Moreover, the presence of retinopathy and CAD was the strongest predictor of mortality than $\mathrm{CAD}$, retinopathy, and microalbuminuria during the long-term follow-up period. Other studies indicated that retinopathy is a stronger predictor of mortality. Van Hecke et al found that individuals with no proliferative DR had a $45 \%$ greater risk and those with proliferative DR had 4 times higher risk of mortality than individuals without DR. ${ }^{40}$

It seems that numerous factors are involved in the development of microvascular and macrovascular complications in diabetes mellitus. Hyperglycemia is one of the important factors. Hyperglycemia activates polyol and hexosamine pathways and accelerates glycosylation of the proteins. The 
glycosylated proteins increase the production of growth factors, angiotensin II and have a prominent role in vascular proliferation in retinopathy. Moreover, the presence of hyperglycemia, increase in the activation of protein kinase $\mathrm{C}$, oxidative stress, and cytokines induced endothelial dysfunction which is a key point in the development of microvascular and macrovascular complications. Furthermore, epigenetic factors and microRNA may be involved in the complications of diabetes mellitus. ${ }^{41}$ This may be justified with previous finding which showed that retinopathy of diabetes is a relatively late onset of complications of diabetes mellitus and may be a sign of poor control of diabetes. Moreover, this finding may be related to this fact that retinopathy is easily recognized by the clinician; however, cardiovascular involvement, particularly in individuals with diabetes may remain silent until the end-outcomes/late stages of the disease.

This study has several limitations worth noting. First, we did not address the type of retinopathy in our analysis as previous studies reported that different grades of diabetes retinopathy (proliferative than non-proliferative diabetes retinopathy) have different risks of all-cause mortality. ${ }^{42}$ Furthermore, due to reversible transition, the sample size for the transition from microalbuminuria to mortality was small; thus, a wide confidence interval was observed. Moreover, we only considered three complications in our model, while other complications such as stroke and neuropathy may affect the results. Although diabetic neuropathy is linked to late complications of diabetes in terms of huge morbidity and mortality, however, our patients used to refer to private clinics (neurologists) for their neurologic evaluations, and therefore, we did not have access to the exact data about of their neurologic examination findings. This is the reason for excluding diabetic neuropathy in the model which is an important limitation of our study.

Finally, in our MSM model, there was no state for patients whose conditions were getting aggravated without going to the next state which could happen in real-life situations. The multistate model construction often requires a high level of detail with data.

The application of multistate models as useful tools for progressive diseases is rapidly growing. Multistate model predicts the probability of transition from one state to another. Furthermore, due to the presence of intermediate events, it also provides more details on the nature and transition of chronic disease's state over time. In this study, the adequacy and goodness of fit of the models were evaluated.
Considering a wider spectrum of diabetes complications in future cohort studies may provide more sound results. The results of this study revealed the importance of controlling hypertension and hyperlipidemia as well as controlling the plasma glucose in order to prevent diabetic complications. Policymakers at national and regional can improve diabetes control at the community level by designing and implanting models of care and active control in diabetic clinics which may decrease the burden and cost of diabetes.

\section{Conclusion}

In addition to glycemic control, our study indicates that controlling hypertension and hyperlipidemia is more effective in reducing mortality and the diabetic macro- and microvascular complications. It seems that different types of complications of diabetes are a function of duration of diabetes. Several factors are involved in the prediction of endpoint outcomes such as mortality. Developing DR and CAD might be the most important complications in predicting mortality in the next 15 years. We also found that poor control of diabetes mellitus (higher HbA1C) is a strong predictor of complications and mortality in the next few years. Furthermore, LDL-cholesterol is related to complications and mortality. In our study, BMI had a preventive role in mortality among individuals with diabetes which may indicate an obesity paradox.

\section{Data Sharing Statement}

The data used in the present study are available upon request.

\section{Ethics Approval and Informed Consent}

The study protocol follows the guidelines of the Iranian government for epidemiological studies in accordance with the Helsinki Declaration. The ethical approval for this study was obtained from the Endocrine and Metabolism Research Center, Isfahan University of Medical Sciences and the University of Tarbiat Modares, Iran (no. IR.MODARES.REC.1397.048). Informed consent was obtained from all participants.

\section{Acknowledgments}

The authors would like to thank all participants. The authors gratefully acknowledge the Isfahan Endocrine and Metabolism Research Center for providing the data. This paper is a part of a Ph.D. dissertation in biostatistics at Tarbiat Modares University. 


\section{Author Contributions}

All authors contributed to data analysis, drafting and revising the article, gave final approval of the version to be published, and agree to be accountable for all aspects of the work.

\section{Disclosure}

The authors report no conflicts of interest in this work.

\section{References}

1. Chen L, Magliano DJ, Zimmet PZ. The worldwide epidemiology of type 2 diabetes mellitus - present and future perspectives. Nat Rev Endocrinol. 2012;8(4):228-236. doi:10.1038/nrendo.2011.183

2. Zheng Y, Ley SH, Hu FB. Global aetiology and epidemiology of type 2 diabetes mellitus and its complications. Nat Rev Endocrinol. 2018;14(2):88-98. doi:10.1038/nrendo.2017.151

3. Chawla A, Chawla R, Jaggi S. Microvascular and macrovascular complications in diabetes mellitus: distinct or continuum? Indian $J$ Endocrinol Metab. 2016;20(4):546-551. doi:10.4103/22308210.183480

4. Solomon SD, Chew E, Duh EJ, et al. Diabetic retinopathy: a Position Statement by the American Diabetes Association | diabetes Care. Available from: https://care.diabetesjournals.org/content/40/3/412. abstract. Accessed October 9, 2019.

5. Kosiborod M, Gomes MB, Nicolucci A, et al. Vascular complications in patients with type 2 diabetes: prevalence and associated factors in 38 countries (the DISCOVER study program). Cardiovasc Diabetol. 2018;17(1):150. doi:10.1186/s12933-018-0787-8

6. Moradi Y, Baradaran HR, Djalalinia S, et al. Complications of type 2 diabetes in Iranian population: an updated systematic review and meta-analysis. Diabetes Metab Syndr. 2019;13(3):2300-2312. doi:10.1016/j.dsx.2019.05.018

7. Manaviat MR, Afkhami M, Shoja MR. Retinopathy and microalbuminuria in type II diabetic patients. BMC Ophthalmol. 2004;4(1):9. doi:10.1186/1471-2415-4-9

8. Petrie JR, Guzik TJ, Touyz RM. Diabetes, hypertension, and cardiovascular disease: clinical insights and vascular mechanisms. Can J Cardiol. 2018;34(5):575-584. doi:10.1016/j.cjca.2017.12.005

9. Mooradian AD. Dyslipidemia in type 2 diabetes mellitus. Nat Clin Pract Endocrinol Metab. 2009;5(3):150-159. doi:10.1038/ncpendmet1066

10. Nentwich MM, Ulbig MW. Diabetic retinopathy - ocular complications of diabetes mellitus. World J Diabetes. 2015;6(3):489-499. doi:10.4239/wjd.v6.i3.489

11. Sabanayagam C, Wong TY. Diabetic Retinopathy and Cardiovascular Disease. Karger Medical and Scientific Publishers; 2019.

12. IDF Diabetes Atlas 9th edition 2019. Available from: https://www. diabetesatlas.org/en/. Accessed April 25, 2020.

13. Chatziralli IP, Sergentanis TN, Keryttopoulos P, Vatkalis N, Agorastos A, Papazisis L. Risk factors associated with diabetic retinopathy in patients with diabetes mellitus type 2. BMC Res Notes. 2010;3:153. doi:10.1186/1756-0500-3-153

14. Fong DS, Aiello L, Gardner TW, et al. Retinopathy in diabetes. Diabetes Care. 2004;27(suppl1):s84-s87. doi:10.2337/diacare.27.2007.S84

15. Basi S, Fesler P, Mimran A, Lewis JB. Microalbuminuria in type 2 diabetes and hypertension: a marker, treatment target, or innocent bystander? Diabetes Care. 2008;31(Supplement2):S194-S201. doi: $10.2337 / \mathrm{dc} 08$-s249

16. Currie GE, von Scholten BJ, Mary S, et al. Urinary proteomics for prediction of mortality in patients with type 2 diabetes and microalbuminuria. Cardiovasc Diabetol. 2018;17(1):50. doi:10.1186 s12933-018-0697-9
17. Bjerg L, Hulman A, Carstensen B, Charles M, Jørgensen ME, Witte DR. Development of microvascular complications and effect of concurrent risk factors in type 1 diabetes: a multistate model from an observational clinical cohort study. Diabetes Care. 2018;41 (11):2297-2305. doi:10.2337/dc18-0679

18. Van Den Hout A. Multi-State Survival Models for Interval-Censored Data. Chapman and Hall/CRC; 2016.

19. Cook RJ, Lawless JF. Multistate Models for the Analysis of Life History Data. Chapman and Hall/CRC; 2018.

20. Janghorbani M, Amini M. Hypertension in type 2 diabetes mellitus in Isfahan, Iran: incidence and risk factors. Diabetes Res Clin Pract. 2005;70(1):71-80. doi:10.1016/j.diabres.2005.02.017

21. Goldenberg R, Punthakee Z. Definition, classification and diagnosis of diabetes, prediabetes and metabolic syndrome. Can J Diabetes. 2013;37:S8-S11. doi:10.1016/j.jcjd.2013.01.011

22. Janghorbani M, Amini M, Tavassoli A. Coronary heart disease in type 2 diabetes mellitus in Isfahan, Iran: prevalence and risk factors. Acta Cardiol. 2006;61(1):13-20. doi:10.2143/AC.61.1.2005135

23. Koroshi A. Microalbuminuria, is it so important? Hippokratia. 2007;11(3):105-107.

24. Hadi Alijanvand M, Aminorroaya A, Kazemi I, et al. Crosssectional and longitudinal assessments of risk factors associated with hypertension and moderately increased albuminuria comorbidity in patients with type 2 diabetes: a 9-year open cohort study. Diabetes Metab Syndr Obes. 2019;12:1123-1139. doi:10.2147/ DMSO.S189726

25. Jackson C. Multi-state models for panel data: the msm package for $\mathrm{R}$. J Stat Softw. 2011;38(1):1-28. doi:10.18637/jss.v038.i08

26. Titman AC. Computation of the asymptotic null distribution of goodness-of-fit tests for multi-state models. Lifetime Data Anal. 2009;15(4):519. doi:10.1007/s10985-009-9133-5

27. Ishihara $M$, Yukimura $Y$, Aizawa $T$, Yamada $T$, Ohto $K$, Yoshizawa K. High blood pressure as risk factor in diabetic retinopathy development in NIDDM patients. Diabetes Care. 1987;10 (1):20-25. doi:10.2337/diacare.10.1.20

28. Bae EH, Lim SY, Han K-D, et al. Association between systolic and diastolic blood pressure variability and the risk of end-stage renal disease. Hypertension. 2019;74:HYPERTENSIONAHA-119.

29. Eryd SA, Gudbjörnsdottir S, Manhem K, et al. Blood pressure and complications in individuals with type 2 diabetes and no previous cardiovascular disease: national population based cohort study. BMJ. 2016;354:i4070. doi:10.1136/bmj.i4070

30. Liu Y, Yang J, Tao L, et al. Risk factors of diabetic retinopathy and sight-threatening diabetic retinopathy: a cross-sectional study of 13 473 patients with type 2 diabetes mellitus in mainland China. BMJ Open. 2017;7(9):e016280. doi:10.1136/bmjopen-2017-016280

31. Bathum L, Depont Christensen R, Engers Pedersen L, Lyngsie Pedersen P, Larsen J, Nexøe J. Association of lipoprotein levels with mortality in subjects aged $50+$ without previous diabetes or cardiovascular disease: a population-based register study. Scand $J$ Prim Health Care. 2013;31(3):172-180. doi:10.3109/ 02813432.2013 .824157

32. Zhou Y, Wang C, Shi K, Yin X. Relationship between dyslipidemia and diabetic retinopathy. Medicine (Baltimore). 2018;97:36. doi:10.1097/MD.0000000000012283

33. Ramanathan Amnath S. Correlation of duration, hypertension and glycemic control with microvascular complications of diabetes mellitus at a tertiary care hospital. Integr Mol Med. 2017;4(1). doi:10.15761/IMM.1000272

34. Arambewela MH, Somasundaram NP, Jayasekara HBPR, et al. Prevalence of chronic complications, their risk factors, and the cardiovascular risk factors among patients with type 2 diabetes attending the diabetic clinic at a Tertiary Care Hospital in Sri Lanka. J Diabetes Res. 2018;2018:4504287. doi:10.1155/2018/4504287 
35. Statistical Center of Iran > Population and Housing Censuses. Available from: https://www.amar.org.ir/english/Population-andHousing-Censuses. Accessed September 23, 2019.

36. McEwen LN, Kim C, Karter AJ, et al. Risk factors for mortality among patients with diabetes: the translating research into action for diabetes (TRIAD) Study. Diabetes Care. 2007;30(7):1736-1741. doi: $10.2337 / \mathrm{dc} 07-0305$

37. Han SJ, Boyko EJ. The evidence for an obesity paradox in type 2 diabetes mellitus. Diabetes Metab J. 2018;42(3):179-187. doi:10.40 93/dmj.2018.0055

38. Liu H, Wu S, Li Y, et al. Body mass index and mortality in patients with type 2 diabetes mellitus: a prospective cohort study of 11,449 participants. $J$ Diabetes Comp lications. 2017;31(2):328-333. doi:10.1016/j.jdiacomp.2016.10. 015
39. Zoungas S, Woodward M, Li Q, et al. Impact of age, age at diagnosis and duration of diabetes on the risk of macrovascular and microvascular complications and death in type 2 diabetes. Diabetologia. 2014;57(12):2465-2474. doi:10.1007/s00125-014-3369-7

40. van Hecke MV, Dekker JM, Stehouwer CDA, et al. Diabetic retinopathy is associated with mortality and cardiovascular disease incidence: the EURODIAB prospective complications study. Diabetes Care. 2005;28(6):1383-1389. doi:10.2337/diacare.28.6.1383

41. Farkhondeh T, Samarghandian S, Roshanravan B. Impact of chrysin on the molecular mechanisms underlying diabetic complications. J Cell Physiol. 2019;234(10):17144-17158. doi:10.1002/jcp.28488

42. Zhu X-R, Zhang Y-P, Bai L, Zhang X-L, Zhou J-B, Yang J-K. Prediction of risk of diabetic retinopathy for all-cause mortality, stroke and heart failure: evidence from epidemiological observational studies. Medicine. 2017;96(3).

\section{Publish your work in this journal}

Diabetes, Metabolic Syndrome and Obesity: Targets and Therapy is an international, peer-reviewed open-access journal committed to the rapid publication of the latest laboratory and clinical findings in the fields of diabetes, metabolic syndrome and obesity research. Original research, review, case reports, hypothesis formation, expert opinion and commentaries are all considered for publication. The manuscript management system is completely online and includes a very quick and fair peer-review system, which is all easy to use. Visit http://www.dovepress.com/testimonials.php to read real quotes from published authors.

Submit your manuscript here: https://www.dovepress.com/diabetes-metabolic-syndrome-and-obesity-targets-and-therapy-journal 